\title{
Stomach 'tastes' the food and adjusts its emptying: A neurophysiological hypothesis (Review)
}

\author{
TOMA PAPACOCEA ${ }^{1}$, RALUCA PAPACOCEA ${ }^{2}$, MUGUREL RĂDOI ${ }^{3}$, \\ SILVIU PIȚURU ${ }^{4}$ and DANIELA GABRIELA BALAN ${ }^{5}$ \\ ${ }^{1}$ Department of Neurosurgery, 'St. Pantelimon' Emergency Hospital, 021659 Bucharest; \\ ${ }^{2}$ Department of Physiology I, 'Carol Davila' University of Medicine and Pharmacy, 050474 Bucharest; \\ ${ }^{3}$ Department of Neurosurgery, National Institute of Neurology and Neurovascular Diseases, 041914 Bucharest; \\ ${ }^{4}$ Department of Dental Medicine II, 'Carol Davila' University of Medicine and Pharmacy, 010221 Bucharest; \\ ${ }^{5}$ Department of Physiology III, 'Carol Davila' University of Medicine and Pharmacy, 050474 Bucharest, Romania
}

Received May 1,2020; Accepted June 1, 2020

DOI: $10.3892 /$ etm.2020.8874

\begin{abstract}
The presence of taste receptors and their secondary messengers in stomach raised the possibility that the stomach might play a role in food 'tasting' and consequently, it might initiate specific adaptations of its secretory and motor function. Furthermore, activated taste receptors release a variety of chemical mediators able to modulate the activity of the enteric nervous system (ENS), and also to influence both secretory and motor functions of the stomach. Based on the physiological fundamental structure of a reflex arch, the stimulation of the gastric taste receptors activates sensory neurons of the gastric wall, continues with motor neurons which initiate the contraction of the local smooth muscle fibers. Beyond this, compounds which act on different taste receptors initiate different responses, stimulatory or inhibitory. These interactions may be translated in the gastric ability to selectively evacuate different nutritive compounds into the duodenum. Consequently, sugars could be favored to the detriment of other compounds.
\end{abstract}

\section{Contents}

1. Introduction

2. Stomach possesses taste receptors

3. Taste receptor signaling mechanisms

4. By 'tasting' the food, stomach adjusts its emptying interrelation with gastric motor response

Correspondence to: Professor Raluca Papacocea, Department of Physiology I, 'Carol Davila' University of Medicine and Pharmacy, Bdul Eroilor Sanitari 8, 050474 Bucharest, Romania

E-mail: raluca.papacocea@umfcd.ro

Key words: taste receptors, gastric taste receptors, gastric emptying, extraoral taste receptors, gastric motility

\section{Introduction}

Sugars represent essential constituents of the human cellular structures: membrane glycoproteins, receptors and nucleic acid molecules (DNA) (1). Carbohydrates are essential for the maintenance of the basal metabolic processes within the human metabolism (2) as they represent the preferred fuel for all body cells (3).

The consumption of sugars, as highly palatable nutrients, is associated to their increased energy density (4); this behavior is innate, providing survival of newborns being maintained during childhood (5).

This preference can be partially explained by an addictive effect, based on the activation of a reward complex, which involves the mesolimbic dopamine system (6).

Even though sugar intake reduction is a dominant pressure of today's nutrition (4), they still represent fundamental compounds for a normal life. Moreover, a theory arose, according to which sugar consumption, even in $80 \%$ of caloric ratio, is completely innocuous in physically active populations (2).

Based on the physiological high significance of sugars, the human body presents adaptive mechanisms able to detect (7) select (8) and absorb them (9).

The classical distribution of the taste receptors refers mainly to the tongue (10), but nowadays many other digestive (stomach, duodenum, colon) (11-14) and extradigestive organs (upper airways, lung, testis) (15-18) are also provided.

\section{Stomach possesses taste receptors}

The first gastric and intestinal taste receptors that expressed $\alpha$-gustducin were identified in rats (14). In the stomach, an abundancy of $\alpha$-gustducin expressing cells, located in the gastric mucosa folds and cardia was described (19).

Other gastric localizations for sweet taste receptor are represented by the brush cells of the limiting ridge (14) and by X/A-like cells (20), an abundant type of gastric endocrine cells, which may represent $\sim 20-30 \%$ of the stomach oxyntic 
glands (21). After the identification of $\alpha$-gustducin in these brush cells of the human stomach, the possible direct action of the glucose intake on these taste cells was outlined (22).

\section{Taste receptor signaling mechanisms}

Sweet molecules interact with sweet taste receptors (23), produce GTP that binds to $\alpha$-gustducin and induce the dissociation of the other subunits $(\beta, \gamma)(24)$. They change the level of cAMP and AMP-activated protein kinase (AMPK). The classical chain of reaction includes phospholipase C2 (21), diacylglycerol (DAG) and IP3 as second messengers and eventually, intracellular calcium increase (25).

$\mathrm{Ca}^{2+}$ triggers many intracellular pathways. One example is TRPM5 (transient receptor potential cation channel, subfamily $\mathrm{M}$, member 5), which regulates $\mathrm{Ca}^{2+}$ entrance inside the cell. Another one is represented by the monovalent selective cation channel-(CALHM1), the voltage-gated ion channel, calcium homeostasis modulator 1 , which is involved in Adenosine 5'-triphosphate (ATP) release (26). In response to ATP release, $\mathrm{K}^{+}$-ATP channels (KATP) are blocked, causing cell membrane depolarization (27). A third example is CaMK, a calcium-dependent kinase that activates exocytoses of glucagon-like peptide-1 (GLP-1). GLP-1 may act as a paracrine agent (28), but also as a hormone (29); it crosses the blood-brain barrier through simple diffusion and it may activate the central GLP-1 receptors (30). In response, the activation of the non-adrenergic non-cholinergic (NANC) system produces a change in the pattern of the gastric myoelectric activity, translated into a gastric emptying delay (31). ATP is a non-adrenergic non-cholinergic transmitter that acts through $\mathrm{P} 2 \mathrm{X}$ and $\mathrm{P} 2 \mathrm{Y}$ receptors of the myenteric plexus (32).

Sweet taste receptor molecules are also present on the enteroendocrine cell surface; in the stomach, receptors T1R1/T1R3 type were described at the apical pole of a very frequent endocrine cell type: $\mathrm{A} / \mathrm{X}$-like cells in rat and $\mathrm{P} / \mathrm{D}$ cells in humans (33). These cells release ghrelin, des-acyl ghrelin, obestatin and nesfatin-1 (34).

\section{By 'tasting' the food, stomach adjusts its emptying - interrelation with gastric motor response}

The presence of the taste receptors and their secondary messengers in the stomach raised the possibility that the stomach might play a role in food 'tasting' and, consequently, it might initiate specific adaptations of its secretory and motor function. In addition, the effect of the taste receptors in releasing GLP-1 and ATP may modulate the activity of the enteric nervous system (ENS) in many ways, with both secretory and motor responses.

Following the sensory neurons stimulation, these neurons activate excitatory or inhibitory motor neurons, regulating the motor pattern in different parts of the stomach, while also modulating the gastric emptying (35). The latter represents a complex process, regulated by ingested food through neural components and neurohormonal mechanisms $(36,37)$.

The gastric emptying rate is influenced by factors such as the gastric content consistency, osmolarity, temperature (38) and it is also correlated to digestion and absorption rates (19).
However, through taste receptors, the stomach not only regulates its own emptying, but we believe that it may also adjust the sequence in which a nutrient type from the ingested food is emptied preferentially into duodenum. Lipid, proteic and sweet could interact with taste receptors and could induce a specific motility pattern, which selects and preferentially eliminates some compounds into the duodenum before other nutrients (lipids or proteins). Sweet compounds interact with sweet taste receptors, associated to high caloric food content (18).

Our theory is that, by activating sweet receptors and by increasing the intracellular calcium concentration, glucose activates the local motility in gastric wall. This could be in relation with the new gastric emptying pattern consisting of a preferential road that orients mainly sugars directly toward the duodenum; the presence of such a pathway was generally described as Magenstrasse by Pal et al (39), but was not related with selection of sugars before.

Sweet taste receptors induce the appearance of this rapid 'slide' way of gastric emptying, possibly like the one described as a physiological Magenstrasse. This way, sweet substances could be rapidly selected and evacuated into the duodenum in contrast to others (proteic and lipidic compounds), which are 'kept' inside the stomach for digestion. In the duodenum, the sweet compounds activate GLP-1 release, which delay the gastric emptying (40), by closing a regulatory feedback loop (41).

The idea of sugar selection and early evacuation into the duodenum by the stomach is also sustained by the observation of the previous mentioned study according to which antral contraction waves produce a longer or a shorter, a larger or a thinner Magenstrasse control of which compounds are emptied out of the stomach earlier and which later (39).

There are many possible reasons for this behavior, starting with the absence of the digestive enzymes for sugars in the stomach (42) and ending with the longer protein and lipid digestion $(43,44)$.

Another reason for a preferential choice of carbohydrates is represented by the classical observation that they are preferred nutrients for all body cells, as long as glucose is metabolized to $\mathrm{H}_{2} \mathrm{O}$ and $\mathrm{CO}_{2}$ and most of the absorbed monosaccharides are converted by the liver into glucose.

Overall, the presence of taste receptors in the entire digestive tube may have the role of adjusting the intensity, duration and length of the peristaltic waves. In this manner, peristaltic waves not only mix and propel, but also orient and redirect different flows of components to different parts of the digestive tube, where specific enzymes are organized in clusters (45). As a result, different nutrients digestion and absorption may preferentially take place and the optimum occurs in certain territories, in relation to body requirements. We advance the idea that sweet compounds of the gastric content are 'selected' by the gastric mucosa, and, through communication with local motor neural network, certain folds are 'built' in order to direct sugars to the duodenum. Other compounds, such as lipids and proteins, are kept for a longer time in the stomach, through the activation of other specific motility patterns, in other parts of the stomach (38). This hypothesis is sustained by a recent observation affirming that only the sweet compounds do not inhibit the gastric myoelectrical activity, compared with sour, salty and bitter substances (37). At the same time, intragastric 
distribution of the proteins and lipid keeps them inside for a longer time, by delaying their emptying (46). Indeed, it has been shown that high fat diets reduce motility by increasing the number of nitrergic inhibitory motor neurons of the ENS $(42,47)$.

The stomach's ability to generate different motility patterns and sequences in different gastric areas at the same time, as a response to local ingested compounds 'tasting', requires further studies, and it may impact certain clinical practice fields.

\section{Acknowledgements}

Professional editing, linguistic and technical assistance was provided by Irina Radu, Individual Service Provider, certified translator in Medicine and Pharmacy (certificate credentials: Series E no. 0048).

\section{Funding}

No funding was received.

\section{Availability of data and materials}

Not applicable.

\section{Authors' contributions}

RP, TP, MR, SP were involved in the conception of the study. RP, TP and DGB revised the manuscript critically for important intellectual content. DGB was responsible for the literature research and the writing of the manuscript. All authors read and approved the final manuscript.

\section{Ethics approval and consent to participate}

Not applicable.

\section{Patient consent for publication}

Not applicable.

\section{Competing interests}

The authors declare that they have no competing interests.

\section{References}

1. Watson H: Biological membranes. Essays Biochem 59: 43-69, 2015.

2. Archer E: Progress in cardiovascular diseases in defense of sugar: A critique of diet-centrism. Prog Cardiovasc Dis 61: 10-19, 2018

3. Jayasinghe SN, Kruger R, Walsh DCI, Cao G, Rivers S, Richter M and Breier BH: Is sweet taste perception associated with sweet food liking and intake? Nutrients 9: 1-19, 2017.

4. Ferreira JG, Tellez LA, Ren X, Yeckel CW and de Araujo IE: Regulation of fat intake in the absence of flavour signalling. J Physiol 590: 953-972, 2012.

5. Nicklaus S: The role of food experiences during early childhood in food pleasure learning. Appetite 104: 3-9, 2016

6. de Jong J, Vanderschuren L and Adan R: The mesolimbic system and eating addiction: What sugar does and does not do. Curr Opin Behav Sci 9: 118-125, 2016.
7. San Gabriel AM: Taste receptors in the gastrointestinal system. Flavour (Lond) 4: 14, 2015.

8. Yoshida R, Niki M, Jyotaki M, Sanematsu K, Shigemura N and Ninomiya Y: Modulation of sweet responses of taste receptor cells. Semin Cell Dev Biol 24: 226-231, 2013.

9. Pang G, Xie J, Chen Q and Hu Z: How functional foods play critical roles in human health. Food Sci Hum Wellness 1: 26-60, 2012.

10. Tsujimoto T: Effects of tastes and taste receptors. Int J Cardiol 260: 195, 2018.

11. Iatridi V, Hayes JE and Yeomans MR: Reconsidering the classification of sweet taste liker phenotypes: A methodological review. Food Qual Prefer 72: 56-76, 2019.

12. Saltiel MY,KuhreR,Christiansen C,Eliasen R,Conde-Frieboes K, Rosenkilde $\mathrm{M}$ and Holst $\mathrm{J}$ : Sweet taste receptor activation in the gut is of and GIP secretion. Nutrients 9: 418, 2017.

13. Rozengurt N, Wu SV, Chen MC, Huang C, Sternini C and Rozengurt E: Colocalization of the $\alpha$-subunit of gustducin with PYY and GLP-1 in L cells of human colon. Am J Physiol Gastrointest Liver Physiol 291: G792-G802, 2006.

14. Hass N, Schwarzenbacher K and Breer H: A cluster of gustducin-expressing cells in the mouse stomach associated with two distinct populations of enteroendocrine cells. Histochem Cell Biol 128: 457-471, 2007.

15. Freund JR and Lee RJ: Taste receptors in the upper airway. World J Otorhinolaryngol Head Neck Surg 4: 67-76, 2018.

16. Gilca M and Dragos D: Extraoral taste receptor discovery: New light on ayurvedic pharmacology. Evid Based Complement Alternat Med 2017: 5435831, 2017.

17. An SS and Liggett SB: Taste and smell GPCRs in the lung: Evidence for a previously unrecognized widespread chemosensory system. Cell Signal 41: 82-88, 2018.

18. Li F: Taste perception: From the tongue to the testis. Mol Hum Reprod 19: 349-360, 2013.

19. Höfer D, Püschel B and Drenckhahn D: Taste receptor-like cells in the rat gut identified by expression of alpha-gustducin. Proc Natl Acad Sci USA 93: 6631-6634, 1996.

20. Trivedi BP: Neuroscience: Hardwired for taste. Nature 486: S7-S9, 2012.

21. Yu R, Li Z, Liu S, Huwatibieke B, Li Y, Yin Y and Zhang W: Activation of mTORC1 signaling in gastric X/A-like cells induces spontaneous pancreatic fibrosis and derangement of glucose metabolism by reducing ghrelin production. EBioMedicine 36: 304-315, 2018

22. Kokrashvili Z, Mosinger B and Margolskee RF: Taste signaling elements expressed in gut enteroendocrine cells regulate nutrient-responsive secretion of gut hormones. Am J Clin Nutr 90: 822S-825S, 2009.

23. Roper SD and Chaudhari N: Taste buds: Cells, signals and synapses. Nat Rev Neurosci 18: 485-497, 2017.

24. Di Pizio A, Ben Shoshan-Galeczki Y, Hayes JE and Niv MY: Bitter and sweet tasting molecules: It's complicated. Neurosci Lett 700: 56-63, 2019.

25. Ekstrand B, Young JF and Rasmussen MK: Taste receptors in the gut - A new target for health promoting properties in diet. Food Res Int 100: 1-8, 2017.

26. Welcome MO, Mastorakis NE and Pereverzev VA: Sweet taste receptor signaling network: Possible implication for cognitive functioning. Neurol Res Int 2015: 606479, 2015.

27. Roper SD: Taste buds as peripheral chemosensory processors. Semin Cell Dev Biol 24: 71-79, 2013.

28. Holmes GM, Browning KN, Tong M, Qualls-Creekmore E and Travagli RA: Vagally mediated effects of glucagon-like peptide s1: In vitro and in vivo gastric actions. J Physiol 587: 4749-4759, 2009.

29. Donnelly D: The structure and function of the glucagon-like peptide-1 receptor and its ligands. Br J Pharmacol 166: 27-41, 2012.

30. Gej1 M, Lerche S, Egefjord L, Brock B, Møller N, Vang K, Rodell AB, Bibby BM, Holst JJ, Rungby J, et al: Glucagon-like peptide-1 (GLP-1) raises blood-brain glucose transfer capacity and hexokinase activity in human brain. Front Neuroenergetics 5: 2, 2013.

31. Lu Z, Yeung CK, Lin G, Yew DTW, Andrews PLR and Rudd JA: Centrally located GLP-1 receptors modulate gastric slow waves and cardiovascular function in ferrets consistent with the induction of nausea. Neuropeptides 65: 28-36, 2017.

32. Bornstein JC: Purinergic mechanisms in the control of gastrointestinal motility. Purinergic Signal 4: 197-212, 2008. 
33. Wideman TH, Zautra AJ and Edwards RR: Re-thinking the fear avoidance model: Toward a multi-dimensional framework of pain-related disability. NIH Public Access 154: 2262-2265, 2014

34. Norris AW and Uc A: A novel stomach-pancreas connection: More than physical. EBioMedicine 37: 25-26, 2018.

35. Spencer NJ, Hibberd TJ, Travis L, Wiklendt L, Costa M, Hu H, Brookes SJ, Wattchow DA, Dinning PG, Keating DJ, et al: Identification of a rhythmic firing pattern in the enteric nervous system that generates rhythmic electrical activity in smooth muscle. J Neurosci 38: 5507-5522, 2018.

36. Marathe CS, Rayner CK, Jones KL and Horowitz M: Effects of GLP-1 and incretin-based therapies on gastrointestinal motor function. Exp Diabetes Res 2011: 279530, 2011.

37. Waluga M, Jonderko K, Domosławska E, Matwiejszyn A, Dzielicki M, Krusiec-Świdergoł B and Kasicka-Jonderko A Effects of taste stimulation on gastric myoelectrical activity and autonomic balance. Saudi J Gastroenterol 24: 100-108, 2018.

38. Goyal RK, Guo Y and Mashimo H: Advances in the physiology of gastric emptying. Neurogastroenterol Motil 31: e13546, 2019.

39. Pal A, Brasseur JG and Abrahamsson B: A stomach road or 'Magenstrasse' for gastric emptying. J Biomech 40: 1202-1210, 2007.

40. Nakatani Y, Maeda M, Matsumura M, Shimizu R, Banba N, Aso Y, Yasu T and Harasawa H: Effect of GLP-1 receptor agonist on gastrointestinal tract motility and residue rates as evaluated by capsule endoscopy. Diabetes Metab 43: 430-437, 2017.
41. Young RL: Sensing via intestinal sweet taste pathways. Front Neurosci 5: 23, 2011

42. Van Den Abeele J, Rubbens J, Brouwers J and Augustijns P: The dynamic gastric environment and its impact on drug and formulation behaviour. Eur J Pharm Sci 96: 207-231, 2017.

43. Soares A, Beraldi EJ, Ferreira PEB, Bazotte RB and Buttow NC: Intestinal and neuronal myenteric adaptations in the small intestine induced by a high-fat diet in mice. BMC Gastroenterol 15: 3, 2015.

44. Janssen S and Depoortere I: Nutrient sensing in the gut: New roads to therapeutics? Trends Endocrinol Metab 24: 92-100, 2013.

45. Danielsen EM and van Deurs B: Galectin-4 and small intestinal brush border enzymes form clusters. Mol Biol Cell 8: 2241-2251, 1997.

46. Marciani L, Cox EF, Pritchard SE, Major G, Hoad CL, Mellows M, Hussein MO, Costigan C, Fox M, Gowland PA, et al: Additive effects of gastric volumes and macronutrient composition on the sensation of postprandial fullness in humans. Eur J Clin Nutr 69: 380-384, 2015.

47. Schemann M, Rohn M and Michel K: Motor control of the stomach. Eur Rev Med Pharmacol Sci 12 (Suppl 1): 41-51, 2008. 